\title{
Inhalt
}

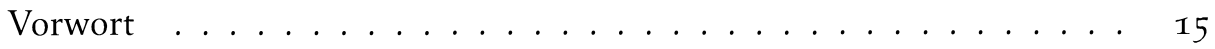

Umschrift und Lautwerte arabischer Buchstaben $\ldots \ldots \ldots \ldots$

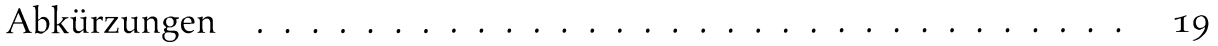

Der Koran . . . . . . . . . . . . . . . . . . . . . . . . . . . 19

Die Bibel . . . . . . . . . . . . . . . . . . . . . . . . . . . . 19

Arabische Kommentare . . . . . . . . . . . . . . . . . . . . . . 19

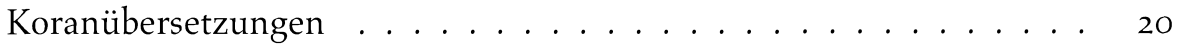

Allgemeine Literatur . . . . . . . . . . . . . . . . 20

Jüdische und christliche Literatur . . . . . . . . . . . . . 21

Altes Testament 21 -Rabbinische Texte 22 -Neues Testament 22

Allgemeine Abkürzungen $\ldots \ldots \ldots \ldots 23$

Zeitschriften, Lexika _ . . . . . . . . . . . . . . . . 23

Die Suren des Korans . . . . . . . . . . . . . . . . . . . . . 24

Hinweise für den Leser . . . . . . . . . . . . . . . . . 27

\section{Wissenschaftlicher Kommentar}

Sure 58: Der Streit (al-Mudjādala), 1-22 . . . . . . . . . . . . . . 29

Bezeichnung und Datierung $\ldots \ldots \ldots$

Struktur und Inhalt . . . . . . . . . . . . . . . . . . . . . . . 29

Vorzüge der Sure 58 . . . . . . . . . . . . . . . . . . . . . . . . . . 29

Kommentar . . . . . . . . . . . . . . . . . . . 45

Sure 59: Die Versammlung (al-Hashr), 1-24 . . . . . . . . . 51

Bezeichnung und Datierung $\ldots \ldots \ldots \ldots \ldots$

Struktur und Inhalt $\ldots \ldots \ldots \ldots$. . . . . . . . . . . 51

Vorzüge der Sure $59 \ldots \ldots \ldots \ldots$. . . . . . . . . . . . . . 51

Kommentar . . . . . . . . . . . . . . . . . 66

Sure 60: Die Prüfung (al-Mumtahina), 1-13 . . . . . . . . 71

Bezeichnung, Datierung, Inhalt / Vorzüge der Sure $60 \ldots \ldots 71$

Kommentar . . . . . . . . . . . . . . . . . . 84 
Sure 61: Die Reihe (al-Ṣaff), $1-14 \ldots \ldots . \ldots . \ldots 8$

Bezeichnung und Datierung / Vorzüge der Sure 61 . . . . . . . . . . . . . . 88

Kommentar . . . . . . . . . . . . . . . . . . . . . 96

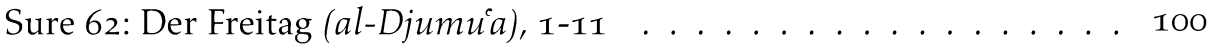

Bezeichnung und Datierung / Vorzüge der Sure $62 \ldots \ldots$. . . . . 100

Kommentar . . . . . . . . . . . . . . . . . . . 107

Sure 63: Die Heuchler (al-Munāfiqūn), 1-11 . . . . . . . . . 110

Bezeichnung und Datierung / Vorzüge der Sure 63 . . . . . . . . . 110

Kommentar . . . . . . . . . . . . . . . . . . . . 117

Sure 64: Die Übervorteilung (al-Taghābun), 1-18 . . . . . . . . . . 120

Bezeichnung, Datierung, Inhalt / Vorzüge der Sure 64 . . . . . . . 120

Kommentar . . . . . . . . . . . . . . . . . . . . . 129

Sure 65: Die Entlassung (al-Ṭalāq), 1-12 . . . . . . . . . . . 133

Bezeichnung, Datierung, Inhalt / Vorzüge der Sure 65 . . . . . . . . 133

Kommentar . . . . . . . . . . . . . . . . . . . . 144

Sure 66: Das Verbot (al-Tahrim), 1-12 . . . . . . . . . . . 148

Bezeichnung, Datierung, Inhalt / Vorzüge der Sure 66 . . . . . . . . I48

Kommentar . . . . . . . . . . . . . . . . . . 158

Sure 67: Die Königsherrschaft $(a l-M u l k), 1-30 \ldots \ldots 162$

Bezeichnung, Datierung, Inhalt / Vorzüge der Sure 67 . . . . . . . . 162

Kommentar . . . . . . . . . . . . . . . . . . . 173

Exkurs: Islamische Schöpfungslehre . . . . . . . . . . . . . . 174

Sure 68: Das Schreibrohr (al-Qalam), 1-52 … . . . . . . 185

Bezeichnung, Datierung, Inhalt / Vorzüge der Sure 68 . . . . . . . 185

Kommentar . . . . . . . . . . . . . . . . . . . . 198

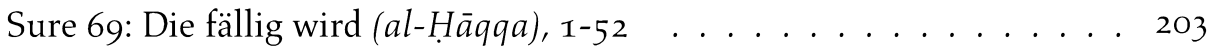

Bezeichnung, Datierung, Inhalt / Vorzüge der Sure 69 . . . . . . . . 203

Kommentar . . . . . . . . . . . . . . . . . 213 
Sure 70: Die Himmelsleiter (al-Mäāidj), 1-44 . . . . . . . . . . 218

Bezeichnung, Datierung, Inhalt / Vorzüge der Sure 70 . . . . . . . . 218

Kommentar . . . . . . . . . . . . . . . . . . 227

Sure 71 : Noach (Nūh) $1-28 \ldots \ldots \ldots$. . . . . . . . . 231

Bezeichnung, Datierung, Inhalt / Vorzüge der Sure $71 \ldots$. . . . . . . . 231

Kommentar . . . . . . . . . . . . . . . . . . 24 241

Sure 72: Die Djinn (al-Djinn), 1-28 . . . . . . . . . . . 245

Bezeichnung, Datierung, Inhalt / Vorzüge der Sure 72 . . . . . . . . 245

Kommentar . . . . . . . . . . . . . . . . . . . . . 255

Sure 73: Der sich eingehüllt hat (al-Muzzammil), 1-20 . . . . . . . 260

Bezeichnung, Datierung, Inhalt / Vorzüge der Sure 73 . . . . . . . 260

Kommentar . . . . . . . . . . . . . . . . . . . . . 267

Sure 74: Der sich zugedeckt hat (al-Muddaththir), 1-56 . . . . . . 271

Bezeichnung, Datierung, Inhalt / Vorzüge der Sure 74 . . . . . . . . 271

Kommentar . . . . . . . . . . . . . . . . . . 281

Sure 75: Die Auferstehung (al-Qiyāma), 1-40 . . . . . . . . . . 287

Bezeichnung, Datierung, Inhalt / Vorzüge der Sure $75 \ldots \ldots . . .287$

Kommentar . . . . . . . . . . . . . . . . . . . 295

Sure 76: Der Mensch (al-Insānn), 1-31 _ . . . . . . . . . . . . . 299

Bezeichnung, Datierung, Inhalt / Vorzüge der Sure 76 . . . . . . . . . 299

Kommentar . . . . . . . . . . . . . . . . . . 309

Sure 77: Die gesandt werden (al-Mursalät), 1-50 . . . . . . . . 313

Bezeichnung, Datierung, Inhalt / Vorzüge der Sure 77 . . . . . . . 313

Kommentar . . . . . . . . . . . . . . . . 323

Sure 78: Der Bericht $(a l-N a b a), 1-40 \ldots \ldots 327$

Bezeichnung, Datierung, Inhalt / Vorzüge der Sure 78 . . . . . . . . 327

Kommentar . . . . . . . . . . . . . . . . . . 335

Sure 79: Die entreißen $(a l-N \bar{a} z i \bar{a} t), 1-46 \ldots \ldots 339$

Bezeichnung, Datierung, Inhalt / Vorzüge der Sure 79 . . . . . . . . 339

Kommentar . . . . . . . . . . . . . . . . . . . . . 347 
Sure 80: Er runzelte die Stirn (Abasa), 1-42 . . . . . . . . . . . . 352

Bezeichnung, Datierung, Inhalt / Vorzüge der Sure 80 . . . . . . . . . 352

Kommentar .................... 359

Sure 81: Das Umwinden (al-Takwir), 1-29 . . . . . . . . . . . . 362

Bezeichnung, Datierung, Inhalt / Vorzüge der Sure 81 . . . . . . . . . 362

Kommentar .................. . . 369

Sure 82: Zerbrechen (al-Infițār), 1-19 . . . . . . . . . . . 372

Bezeichnung, Datierung, Inhalt / Vorzüge der Sure 82 . . . . . . . . . 372

Kommentar . . . . . . . . . . . . . . 377

Sure 83: Die das Maß verkürzen (al-Muțaffifīn), 1-36 . . . . . . . 379

Bezeichnung, Datierung, Inhalt / Vorzüge der Sure 83 . . . . . . . . 379

Kommentar ................... . . 387

Sure 84: Sich spalten (al-Inshiqāq), 1-25 . . . . . . . . . . . . 390

Bezeichnung, Datierung, Inhalt / Vorzüge der Sure 84 . . . . . . . . . . 390

Kommentar . . . . . . . . . . . . . . . 397

Sure 85: Die Sternzeichen (al-Burūdj), 1-22 . . . . . . . . . . 400

Bezeichnung, Datierung, Inhalt / Vorzüge der Sure 85 . . . . . . . . . 400

Kommentar . . . . . . . . . . . . . . . 407

Sure 86: Der Nachtstern (al-Ṭāriq), 1-17 . . . . . . . . . . . . 410

Bezeichnung, Datierung, Inhalt / Vorzüge der Sure 86 . . . . . . . . 410

Kommentar ................... . . 415

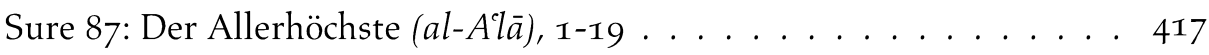

Bezeichnung, Datierung, Inhalt / Vorzüge der Sure 87 . . . . . . . . 417

Kommenmtar . . . . . . . . . . . . . . . 423

Sure 88: Die bedecken wird (al-Ghāshiya), 1-26 . . . . . . . . . 426

Bezeichnung, Datierung, Inhalt / Vorzüge der Sure 88 . . . . . . . . . 426

Kommentar .................... . . 433 
Sure 89: Die Morgenröte (al-Fadjr), 1-30 … . . . . . . . . . 435

Bezeichnung, Datierung, Inhalt / Vorzüge der Sure 89 . . . . . . . 435

Kommentar . . . . . . . . . . . . . . . . . . . . . . . 444

Exkurs: Das koranische Menschenbild . . . . . . . . . . . 446

Sure 90: Das Gebiet (al-Balad), 1-20 . . . . . . . . . . . . . . . 449

Bezeichnung, Datierung, Inhalt / Vorzüge der Sure $90 \quad \ldots \ldots . .449$

Kommentar . . . . . . . . . . . . . . . . . . . . 455

Sure 91: Die Sonne (al-Shams), 1-15 . . . . . . . . . . . . . 457

Bezeichnung, Datierung, Inhalt / Vorzüge der Sure 91 . . . . . . . . . 457

Kommentar . . . . . . . . . . . . . . . . . . . 464 463

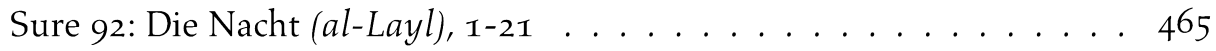

Bezeichnung, Datierung, Inhalt / Vorzüge der Sure $92 \ldots \ldots$. . . . . . 465

Kommentar . . . . . . . . . . . . . . . . 471

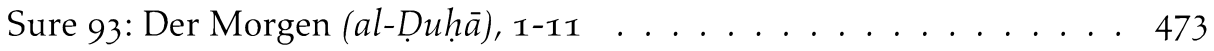

Bezeichnung, Datierung, Inhalt / Vorzüge der Sure 93 . . . . . . . . 473

Kommentar . . . . . . . . . . . . . . . . . . . . . . . . . 479

Sure 94: Das Weiten (al-Sharh), 1-8 . . . . . . . . . . . 481

Bezeichnung, Datierung, Inhalt / Vorzüge der Sure 94 . . . . . . . . 481

Kommentar . . . . . . . . . . . . . . . . . . . . 487

Sure 95: Der Feigenbaum (al-Tīn), 1-8 . . . . . . . . . . . . . . . . . 489

Bezeichnung, Datierung, Inhalt / Vorzüge der Sure 95 . . . . . . . . . 489

Kommentar . . . . . . . . . . . . . . . . . . 495

Sure 96: Der Embryo (al-'Alaq), 1-19 . . . . . . . . . . . . . . . 497

Bezeichnung, Datierung, Inhalt / Vorzüge der Sure 96 . . . . . . . . 497

Kommentar . . . . . . . . . . . . . . . . . 503

Sure 97: Die Bestimmung (al-Qadr), 1-5 . . . . . . . . . . 505

Bezeichnung, Datierung, Inhalt / Vorzüge der Sure 97 . . . . . . . 505

Kommentar . . . . . . . . . . . . . . . 5 511 
Sure 98: Das deutliche Zeichen (al-Bayyina), 1-8 . . . . . . . . 512

Bezeichnung, Datierung, Inhalt / Vorzüge der Sure $98 \ldots \ldots$. . . . . 512

Kommentar . . . . . . . . . . . . . . . . . . 517

Sure 99: Das Beben (al-Zalzala), 1-8 . . . . . . . . . . . . . 519

Bezeichnung, Datierung, Inhalt / Vorzüge der Sure 99 . . . . . . . 519

Kommentar . . . . . . . . . . . . . . . . . . 525

Sure 100: Die laufen (al-'Ádiyāt), 1-11 . . . . . . . . . . . . . 527

Bezeichnung, Datierung, Inhalt / Vorzüge der Sure 100 . . . . . . . 527

Kommentar . . . . . . . . . . . . . . . . . . 533

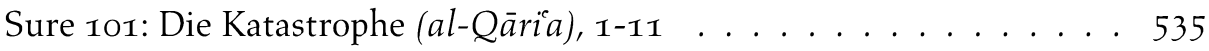

Bezeichnung, Datierung, Inhalt / Vorzüge der Sure $101 \ldots \ldots$

Kommentar . . . . . . . . . . . . . . . . 54 54

Sure 102: Wettstreit um noch mehr (al-Takāthur), 1-8 . . . . . . 542

Bezeichnung, Datierung, Inhalt / Vorzüge der Sure $102 \ldots \ldots 42$

Kommentar . . . . . . . . . . . . . . . . . . . . 5 547

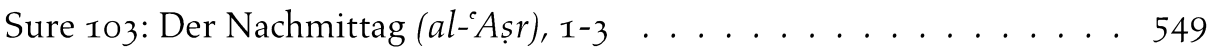

Bezeichnung, Datierung, Inhalt / Vorzüge der Sure 103 . . . . . . . 549

Kommentar . . . . . . . . . . . . . . . . . 555

Sure 104: Der Stichler (al-Humaza), 1-9 . . . . . . . . . . . 556

Bezeichnung, Datierung, Inhalt / Vorzüge der Sure 104 . . . . . . . 556

Kommentar . . . . . . . . . . . . . . . . . 561

Sure 105: Der Elefant $(a l-F i l), 1-5 \ldots \ldots \ldots 62$

Bezeichnung, Datierung, Inhalt / Vorzüge der Sure $105 \ldots \ldots$

Kommentar . . . . . . . . . . . . . . . . . . . 567

Sure 106: Quraysh, 1-4 . . . . . . . . . . . . . . . . . 568

Bezeichnung, Datierung, Inhalt / Vorzüge der Sure $106 \ldots \ldots$

Kommentar . . . . . . . . . . . . . . . . . . . 573

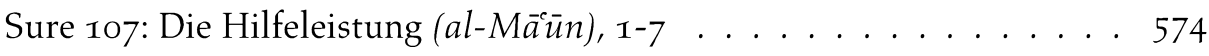

Bezeichnung, Datierung, Inhalt / Vorzüge der Sure 107 . . . . . . . 574

Kommentar . . . . . . . . . . . . . . . . . . . . . . . . 579 
Sure 108: Die Fülle (al-Kauthar), 1-3 . . . . . . . . . . 580

Bezeichnung, Datierung, Inhalt / Vorzüge der Sure 108 . . . . . . . . 580

Kommentar . . . . . . . . . . . . . . . . . . . 585

Sure 109: Die Ungläubigen (al-Kāfirūn), 1-6 . . . . . . . . . . 586

Bezeichnung, Datierung, Inhalt / Vorzüge der Sure 109 . . . . . . . 586

Kommentar . . . . . . . . . . . . . . . . . . 591

Sure 110: Die Unterstützung (al-Nașr), 1-3 . . . . . . . . . . . 592

Bezeichnung, Datierung, Inhalt / Vorzüge der Sure 110 . . . . . . 592

Kommentar . . . . . . . . . . . . . . . . . . . . . 597

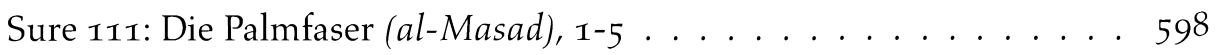

Bezeichnung, Datierung, Inhalt / Vorzüge der Sure 111 . . . . . . 598

Kommentar . . . . . . . . . . . . . . . . . 603

Sure 112: Der aufrichtige Glaube (al-Ikhlāṣ), 1-4 . . . . . . . . . . . 605

Bezeichnung, Datierung, Inhalt / Vorzüge der Sure $112 \ldots \ldots 5$

Kommentar . . . . . . . . . . . . . . . . . . 611

Sure 113 : Das Frühlicht (al-Falaq), $1-5 \ldots \ldots . \ldots 612$

Bezeichnung, Datierung, Inhalt / Vorzüge der Sure 113 . . . . . . 612

Kommentar . . . . . . . . . . . . . . . . . . 617

Sure 114: Die Menschen (al-Nās), 1-6 . . . . . . . . . . . 618

Bezeichnung, Datierung, Inhalt / Vorzüge der Sure $114 \ldots \ldots 18$

Kommentar . . . . . . . . . . . . . . . . . . . 623

Bibliographie . . . . . . . . . . . . . . . . . . 624

Register . . . . . . . . . . . . . . . . 626

Koranstellen . . . . . . . . . . . . . . . . . . . . 626

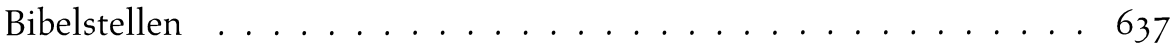

Personen . . . . . . . . . . . . . . . . . 638 
